\title{
O ENSINO DE QUÍMICA E A FORMAÇÃO DO EDUCADOR QUÍMICO, SOB O OLHAR BACHELARDIANO
}

\section{Chemistry teaching and chemistry teacher education from a bachelardian point of view}

\author{
Soraia Freaza Lôbo ${ }^{1}$
}

\begin{abstract}
Resumo: Apresentam-se alguns elementos da epistemologia histórica do filósofo Gaston Bachelard para a discussão de aspectos relativos ao ensino de Química e à formação do educador químico. Com base em alguns aspectos relativos ao processo de produção da ciência Química, procura-se mostrar como determinadas concepções epistemológicas, como o realismo ingênuo, o substancialismo e o racionalismo clássico, foram historicamente superadas e, no entanto, ainda estão presentes no ensino de Química. Nesta perspectiva, o artigo apresenta alguns conceitos da epistemologia bachelardiana, como o de polaridade epistemológica, vigilância epistemológica e perfil epistemológico e os insere em questões que têm sido, atualmente, discutidas para o ensino e a formação do professor, com destaque para a noção de perfil conceitual de Mortimer e sua utilização como recurso didático no ensino de ciências.
\end{abstract}

Palavras-chave: Ensino de Química. Formação do professor de ciências. Concepções epistemológicas.

\begin{abstract}
In the present article some elements of Gaston Bachelard's historical epistemology are presented in order to discuss some aspects regarding chemistry teaching and chemistry teacher education. Based on some aspects related to the production process in chemical science, we aim to show how specific epistemological conceptions such as naive realism, substantialism, and classical rationalism were historically overcome; however, they are still present in textbooks and chemistry manuals. With this in mind, this article presents some concepts of bachelardian epistemology, such as epistemological polarity, epistemological surveillance and epistemological profiles and inserts them into questions which have been recently discussed for teaching and teacher education, emphasizing Mortimer's conceptual teaching profile and its usage as a didactic resource in science teaching.
\end{abstract}

Key words: Chemistry teaching. Science's teacher education. Epistemological conceptions.

${ }^{1}$ Bacharel em Química; doutora em Educação; professora adjunta, Instituto de Química, Universidade Federal da Bahia. Salvador, Ba. <soraia@ufba.br>

Alameda dos Jasmins, n. 88, Condomínio Jardim das Mangueiras, ap. 1301

Candeal - Salvador, Ba.

40.296-200 


\section{Lôbo, S. F.}

Sob a perspectiva da epistemologia bachelardiana, o ensino de Química tem sido objeto de discussão de vários autores (LÔBO, 2002; MORTIMER, 1997; LOPES, 1993, 1992). Estes trabalhos têm focalizado elementos da epistemologia de Bachelard para discutir questões relevantes do ensino de Química e, de modo geral, de Ciências. No presente artigo esses elementos aparecem articulados às atuais questões relativas ao ensino de Química, e, também, à formação do professor, numa perspectiva de formação docente mais autônoma, reflexiva e voltada para a pesquisa.

A história de vida de Bachelard mostra sua preocupação constante com as questões referentes ao ensino de Ciências e à Educação, de modo geral, embora não tenha deixado obras específicas sobre este tema. Sua trajetória como professor de Química e Física do ensino secundário levou-o a situar essas Ciências dentro do debate filosófico, colocando-se tanto contra as perspectivas dos filósofos de sua época como contra a ausência de uma reflexão metafísica no trabalho dos cientistas.

Em sua crítica aos filósofos, Bachelard mostrou a inadequação da aplicação de princípios gerais a problemas científicos específicos. Para ele,

mantendo-se fora do espírito científico, o filósofo pensa que a filosofia das ciências pode limitar-se aos princípios das ciências, aos temas gerais, ou então, limitando-se estritamente aos princípios, o filósofo pensa que a filosofia das ciências tem por missão articular os princípios das ciências com os princípios de um pensamento puro, desinteressado dos problemas da aplicação efetiva. Para o filósofo, a filosofia da ciência nunca está totalmente no reino dos fatos. (BACHELARD, 1991, p. 9)

Em relação aos cientistas, a crítica de Bachelard é dirigida à ausência de reflexões filosóficas sobre suas atividades científicas, exatamente numa época em que as novas descobertas científicas demandavam outro olhar, uma nova razão, mais polêmica, mais questionadora. Para ele,

Os cientistas consideram inútil uma preparação metafísica; declaram aceitar, em primeiro lugar, as lições da experiência se trabalham nas ciências experimentais, ou os princípios da evidência racional se trabalham nas ciências matemáticas. Para eles, a hora da filosofia só chega depois do trabalho efetivo; concebem, pois, a filosofia das ciências como um resumo dos resultados gerais do pensamento científico, como uma coleção de fatos importantes. [...] Para o cientista, a filosofia das ciências ainda está no reino dos fatos. (BACHELARD, 1991, p. 8)

O racionalismo puro dos filósofos e o empirismo sem uma razão que lhe dê sustentação são, para Bachelard, obstáculos epistemológicos que não podem traduzir o caráter dinâmico do pensamento científico contemporâneo, no qual o empirismo e o racionalismo estão totalmente imbricados. Esta polarização ou polaridade epistemológica, longe de ser um dualismo, é prova de que cada uma dessas concepções é o complemento da outra, de forma que, 
para ele, "pensar cientificamente é colocar-se no campo epistemológico intermediário entre teoria e prática, entre matemática e experiência" (BACHELARD, 1991, p. 10).

A partir das descobertas científicas do início do século XX, na área da microfísica, Bachelard coloca-se contra um racionalismo "no vazio" e um empirismo "desconexo" (BACHELARD, 1977, p. 10). Ao defender uma síntese da teoria com a experiência, nas ciências físicas, Bachelard propõe uma filosofia em que o racionalismo aplicado e o materialismo técnico se manifestem, num movimento dialético que represente o verdadeiro pensamento científico.

Bachelard questiona a objetividade no trabalho dos cientistas. Contrariando a positividade atribuída à pesquisa científica, procura mostrar, em suas obras - em especial no livro A Filosofia do Não - como o caráter subjetivo pode interferir na prática científica. Ressalta, então, a necessidade do processo de reflexão sobre esta prática, quando diz que "o espírito pode mudar de metafísica; o que não pode é passar sem a metafísica" (p. 15). Considerando este processo de reflexão relevante, sugere que o epistemólogo faça os seguintes questionamentos aos cientistas:

Como pensais?, quais são as vossas tentativas?, os vossos ensaios, os vossos erros?, Quais são as motivações que vos levam a mudar de opinião? Por que razão vocês se exprimem tão sucintamente quando falam das condições psicológicas de uma nova investigação? Transmitam-nos sobretudo as vossas idéias vagas, as vossas contradições, as vossas idéias fixas, as vossas convicções não confirmadas [...] Digam-nos o que pensam, não ao sair do laboratório, mas sim nas horas em que deixais a vida comum para entrar na vida científica. (BACHELARD, 1991, p. 15)

A preocupação de Bachelard com a necessidade de reflexão filosófica sobre a prática científica é um aspecto que mostra o pioneirismo de suas idéias e a relevância de sua epistemologia para aqueles que lidam com a prática científica e, também, com o ensino de Ciências.

No contexto do ensino, um dos aspectos mais discutidos por educadores em Ciência é a dificuldade de compreensão dos conceitos científicos pelos alunos. No ensino de Química, conceitos derivados da Mecânica Quântica e utilizados na compreensão dos vários aspectos relativos às ligações químicas e à estrutura molecular apresentam alto grau de dificuldade de compreensão, em função da necessidade de maior abstração. Como diz Bachelard, a Química contemporânea não é mais uma ciência de memória, mas uma Química matemática, uma Química teórica, fundada a partir da união com a Física teórica, uma Química teórica-Física teórica. Essa nova Química tem uma racionalidade muito diferente da racionalidade do senso comum, na medida em que rompe com as primeiras impressões, próprias do realismo ingênuo, e se eleva a um nível de complexidade e especialidade que exige uma nova razão em constante mutação, polêmica, como foi e é polêmico o processo de produção do conhecimento científico.

Sendo a Química contemporânea uma ciência descrita por um racionalismo aplicado e um materialismo instruído, ordenado, ela rompe tanto com o racionalismo formal, abstrato, quanto com o materialismo apegado ao fenômeno ou, segundo Bachelard, com o materialismo ingênuo. 
A história da Química mostra uma superação do realismo ingênuo, do materialismo ingênuo, e uma racionalidade cada vez mais progressiva. No entanto, a racionalidade cada vez maior alcançada por este conhecimento se deu por processos de rupturas com concepções anteriores, visando à superação dos obstáculos que impediam o desenvolvimento da razão.

No que se refere ao ensino de Química, é comum a apresentação, apenas, dos resultados dessa Ciência, o conhecimento científico em Química, com suas leis, teorias e modelos que, normalmente, são concebidos como representações da realidade. A ênfase sobre os produtos da Ciência, em detrimento de seus processos de produção, provoca uma série de desdobramentos indesejáveis na pedagogia dessa Ciência, criando obstáculos à sua compreensão. Um desses desdobramentos é o reforço da crença positivista que atribui à Ciência o estabelecimento de leis invariáveis que regem os fenômenos, baseadas na observação e experimentação. A determinação das causas dos fenômenos é considerada especulação metafísica que o espírito humano não pode responder. Nesta perspectiva, para Comte, "o verdadeiro espírito positivo consiste sobretudo em ver para prever, em estudar o que é a fim para daí concluir o que será, segundo o dogma geral da invariabilidade das leis naturais" (COMTE, 1990, p. 19).

O positivismo de Comte encontrou terreno fértil na ciência do século XIX, quando o mecanicismo determinista era suficiente para a compreensão dos fenômenos físicos. No entanto, a partir do início do século XX, a exigência de uma nova razão rompeu as certezas estabelecidas e fundou um novo sistema de pensamento que, ao mesmo tempo em que negava o anterior, limitava seu campo de aplicação. Este novo espírito científico, traduzido por Bachelard por uma filosofia do não, surge, para ele, não como atitude de recusa, mas de conciliação. Como necessidade de romper com os conhecimentos do passado, sem negá-los, mas integrando-os, hierarquizando-os, de forma a contemplar toda a complexidade das ciências físicas contemporâneas e, ao mesmo tempo, mostrar o caráter progressivo e contextual da razão na história dessas Ciências.

A epistemologia histórica de Bachelard procura mostrar que o progresso filosófico das ciências físicas deu-se no sentido de uma racionalidade cada vez mais complexa, rompendo com concepções inadequadas, como o realismo, substancialismo e racionalismo clássico. Nesta perspectiva, o conceito bachelardiano de ruptura epistemológica é fundamental para o ensino das matérias científicas, pois insere os conceitos científicos no contexto histórico em que eles foram produzidos, mostrando os obstáculos epistemológicos inerentes a seus próprios processos de produção.

A importância da historicização no ensino de Ciências é apontada por Lopes (1993), que defende ênfase no estudo dos problemas científicos e não apenas dos resultados científicos. A autora faz uma crítica à forma ilustrativa com que a história é abordada nos livros didáticos de Química, em lugar de apresentar os embates entre idéias e fatos que contribuíram para o progresso científico dessa ciência (LOPES, 1993). Uma perspectiva histórica no ensino das Ciências também tem sido apontada por outros autores (ABD-EL-KHALICK e LEDERMAN, 2000; MATTHEWS, 1994; STINNER e WILLIAMS, 1993) como uma forma de tornar o ensino mais crítico, a partir da compreensão do empreendimento científico como um empreendimento humano e, portanto, sujeito a erros, concepções inadequadas e visões de mundo diferenciadas, a depender da época em que foi produzido.

Estes obstáculos presentes durante a produção do conhecimento também se mani- 
festam no processo de aprendizagem dos conceitos científicos. Nesta perspectiva, segundo Bachelard, a aquisição da cultura científica necessita de uma catarse intelectual e afetiva que a coloque em estado de mobilização permanente (BACHELARD, 1996). Para ele, é preciso questionar constantemente o conhecimento para evitar a sedução das primeiras impressões, da observação primeira, que normalmente se apresenta cheia de imagens, sendo mais concreta, pragmática e, portanto, mais próxima do senso comum. É preciso manter, constantemente, uma vigilância epistemológica que mobilize a razão e a libere dos preconceitos dos conhecimentos mal estabelecidos, porque pouco questionados.

$\mathrm{Na}$ perspectiva apontada, a descontinuidade entre o conhecimento científico e o senso comum, proposta por Bachelard, é um requisito fundamental para a aquisição da cultura científica. Na Química, por exemplo, a utilização de metáforas e analogias como forma de aproximar o conhecimento químico do conhecimento cotidiano é uma prática muito comum nas salas de aula, principalmente no nível médio de ensino. Concepções realistas, substancialistas, puramente empiristas estão sempre presentes no ensino, principalmente quando se trabalha com conceitos mais abstratos para explicar os fenômenos do mundo microscópico. É o que acontece, por exemplo, com o conceito de orbital que, por corresponder a uma função matemática - a função de onda psi $(\psi)$ - e não ter significado físico, é constantemente associada à região em volta do núcleo onde há maior probabilidade de encontrar o elétron. Mesmo admitindo-se hoje a incapacidade de localizar o elétron com precisão e de estabelecer uma trajetória definida para seu movimento, orbital, como conceito quântico, ainda gera, no ensino de Química, certo desconforto e, por isso, é freqüentemente associado ao quadrado da função de onda $(\psi)^{2}$ que, na realidade, corresponde à densidade de probabilidade de encontrar o elétron em uma região em volta do núcleo. A correspondência direta entre o conceito e a imagem é característica de posturas realistas ingênuas ainda presentes no ensino de Química.

Um exemplo de concepção inadequada presente no ensino de Química é o substancialismo nas noções de calor e temperatura. A idéia de que a temperatura é uma medida da quantidade de calor é muito comum entre professores e alunos e revelada, muitas vezes, pela expressão "a reação liberou calor", numa referência a uma reação exotérmica, como significando que a reação contém calor e, por isso, ele será liberado durante o processo.

Mostrando preocupação com o ensino das ciências físicas, Bachelard chama atenção para o fato de os alunos já possuírem conhecimentos empíricos prévios, sedimentados na vida cotidiana, compondo uma cultura específica para cada sujeito. Assim, para ele, não se trata "de adquirir uma cultura experimental, mas sim de mudar de cultura experimental". Essa mudança exige uma "psicanálise dos erros iniciais" para superar os hábitos, crenças e concepções que se distanciam da racionalidade científica contemporânea (BACHELARD, 1996, p. 23).

A ruptura sugerida por Bachelard entre conhecimento científico e senso comum não deve levar à compreensão de que, no ensino de Ciências, o aprendiz deve abandonar os conhecimentos adquiridos em sua vida cotidiana, com os quais ele resolve os problemas do dia a dia, para adquirir uma nova cultura (a científica), aplicável à resolução de qualquer problema, independente do contexto em que ele aparece. A epistemologia bachelardiana, pelo contrário, advoga a necessidade de uma dispersão de concepções filosóficas, um pluralismo filosófico para traduzir o pensamento científico em toda sua complexidade. Afinal, para Bachelard, a ciência cria filosofia e cada problema científico exige uma filosofia particular, específica. Neste sentido, para ele, a filosofia das Ciências deve ser: 
uma filosofia diferencial que contrabalançaria a filosofia integral dos filósofos. Esta filosofia diferencial estaria encarregada de analisar o devir de um pensamento. Em linhas gerais, o devir de um pensamento científico corresponderia a uma normalização, à transformação da forma realista em forma racionalista. (BACHELARD, 1991, p. 16)

Essa discussão procura mostrar que o ensino de Ciências, ao mesmo tempo em que introduz o aluno numa nova cultura - a cultura científica - deve ser suficientemente crítico para questionar os princípios científicos, analisar seu processo de produção, perceber as influências do contexto social e político nessa produção e delimitar o contexto de aplicação do conhecimento científico. Nesta perspectiva, a epistemologia histórica de Bachelard pode contribuir para o desenvolvimento de estratégias de ensino que promovam maior compreensão da natureza da ciência e não se limite, apenas, à transmissão de seus produtos.

Reconhecendo que o desenvolvimento das idéias e dos conceitos científicos não foi homogêneo, Bachelard chama à atenção que nem todos os conceitos científicos atingiram o mesmo grau de maturidade filosófica: alguns permaneceram, ainda, numa fase realista e outros, numa fase empirista ou positivista. $\mathrm{O}$ autor introduz o conceito de progresso filosófico que, apesar de ter pouco significado na filosofia pura, é importante na filosofia das Ciências. Para ele, a evolução do conhecimento científico ordenou a própria filosofia, no sentido de uma complexidade crescente que vai do animismo ao ultra-racionalismo, embora todas as outras concepções filosóficas intermediárias - como o realismo, positivismo e racionalismo clássico - coexistam no pensamento científico (BACHELARD, 1991).

A coexistência de diferentes perspectivas filosóficas para um mesmo conceito científico mostra o pluralismo filosófico das idéias científicas e é descrito por Bachelard por meio da noção de perfil epistemológico. Mediante esta noção, ele procura mostrar como cada conceito científico necessitou de perspectivas filosóficas diferenciadas até atingir um estágio de maturação com o racionalismo dialético da Ciência contemporânea.

A noção de perfil epistemológico, discutida na obra A Filosofia do Não, é utilizada, por Bachelard, para ilustrar sua própria dispersão filosófica em relação aos conceitos de massa e energia (BACHELARD, 1991).

Utilizando a noção de perfil epistemológico é possível mostrar que as diversas filosofias podem estar presentes num mesmo conceito, mesmo quando algumas delas são conscientemente consideradas inadequadas para caracterizar determinada noção científica. Bachelard sugere uma análise filosófica espectral para determinar as várias concepções que acompanharam a evolução do pensamento científico do sujeito analisado, pois, para ele, o desenvolvimento dos conhecimentos de um indivíduo em relação a um conceito científico particular mostra uma ordem semelhante, que corresponde ao progresso filosófico deste conceito em todo seu desenvolvimento histórico (BACHELARD, 1991).

Pode-se inferir que, embora o progresso científico das ciências físicas tenha se dado na direção de uma racionalidade cada vez mais complexa, várias perspectivas filosóficas coexistiram e podem ainda coexistir no processo de produção científica. Esta dispersão filosófica representa, portanto, um espectro das idéias filosóficas de cada conceito e, para Bachelard, "guarda a marca dos obstáculos que uma cultura teve que superar" (BACHELARD, 1991, p. 48). 
Em se tratando da educação científica, observa-se a necessidade de superação de obstáculos, seja epistemológicos ou pedagógicos, nos processos de ensino e aprendizagem. No ensino de Química, a noção de perfil epistemológico tem sido trabalhada de forma bastante original por Mortimer. Reconhecendo que o ensino desta matéria não pode se limitar a princípios e leis (imutáveis) aplicados aos fenômenos químicos (característica do positivismo) e, ao mesmo tempo, considerando a importância da história da Química para a compreensão do processo de produção do conhecimento químico pelo aluno, o autor procura mostrar como a noção de perfil epistemológico pode melhorar o ensino de Química e colaborar para a superação de visões inadequadas presentes, principalmente, nos níveis Fundamental e Médio. A utilização do perfil epistemológico em sala de aula, baseando-se na história da Química como eixo orientador do processo de ensino, contribui para superar o ensino dogmático ainda predominante nas escolas, uma vez que mostra as rupturas que ocorreram ao longo da história da produção desse conhecimento e revela seu caráter essencialmente dinâmico (MORTIMER, 1992).

No trabalho citado acima, o autor faz uma discussão sobre a evolução dos conceitos sobre a estrutura do átomo no período entre a Química Clássica e a Química Moderna, revelando a ruptura ocorrida entre a noção clássica de átomo, como bloco de construção da matéria, e a concepção quântica, na qual o átomo é concebido como constituído de partículas que têm, ao mesmo tempo, característica de onda. Para Mortimer, essa dualidade rompe com os conceitos clássicos da mecânica newtoniana, da mesma forma que a visão clássica da teoria atômica rompe com a visão realista de matéria contínua. Estas diferentes concepções resultaram de diferentes estágios de desenvolvimento científico na Química, tendo sido fundamentais as descobertas da Física, no início do século XX, para a superação do empirismo predominante naquela ciência durante todo o século XIX.

Nessa perspectiva apontada, percebe-se que podem existir várias representações da realidade, tanto para o mesmo sujeito em relação a um conceito científico, quanto para um mesmo conceito, em diferentes contextos históricos. Esta questão é de fundamental importância para o ensino de Química e para a formação do licenciado em Química, na medida em que coloca a questão do ensino e da formação do professor numa abordagem contextual, com base na história e na filosofia da Ciência, contribuindo para um ensino mais crítico, porque apoiado numa concepção de ciência como produto cultural da humanidade e, portanto, sujeito a erros, conflitos e constantes retificações.

Além deste aspecto, acredita-se que esta abordagem relativiza um pouco a idéia de que a aprendizagem em Ciências deve promover a substituição das concepções espontâneas dos alunos pelas concepções científicas, defendida pelos adeptos do modelo de mudança conceitual. Nesse sentido, é interessante a proposta de Linder de que o ensino de ciências caminhe no sentido de "aumentar a capacidade dos estudantes em distinguir entre concepções apropriadas para cada contexto específico" (LINDER, 1993, apud MORTIMER, 1996, p. 9), em lugar de tentar mudar as concepções cotidianas dos alunos, epistemologicamente e ontologicamente diferentes das concepções científicas e já estabilizadas dentro de suas visões de mundo.

Como alternativa ao modelo de mudança conceitual, Mortimer propõe o modelo de mudança de perfil conceitual, como estratégia de ensino de Ciências. Este modelo também 


\section{Lôbo, S. F.}

utiliza a explicitação das idéias dos estudantes sobre os conceitos científicos, porém não para substituí-las, mas para "descrever a evolução das idéias, tanto no espaço social da sala de aula, como nos indivíduos, como conseqüência do processo de ensino" (MORTIMER, 1996, p. 33). Este modelo foi descrito de forma mais detalhada em Mortimer (1995) ${ }^{2}$.

Assim como o perfil epistemológico de Bachelard, o perfil conceitual proposto por Mortimer mostra as diferentes zonas do perfil, de forma que cada zona tem um poder explanatório maior que as anteriores. Dessa forma, o deslocamento para a direita, dentro de um perfil conceitual, significa uma evolução conceitual do aluno.

Um aspecto importante ressaltado por Mortimer é que a noção de perfil conceitual pode mostrar as características epistemológicas e ontológicas dos conceitos científicos (e não apenas as epistemológicas), desde que ambas sofram mudanças ao longo de um mesmo perfil conceitual. Para ele, este aspecto é importante pois muitos problemas na aprendizagem dos conceitos científicos relacionam-se à dificuldade do aluno em mudar as categorias ontológicas relacionadas aos conceitos científicos (MORTIMER, 1996).

O trabalho de Mortimer sobre o perfil conceitual levanta uma das questões mais importantes para quem lida com o ensino de Ciências: a linguagem. A alfabetização científica ${ }^{3}$ requer a aquisição de uma nova linguagem. No entanto, para Cobern (1996), assim como para Vygotsky (1979), há uma forte interação entre a linguagem e o pensamento, de forma que a aquisição de uma nova linguagem implica adquirir uma nova estrutura de pensamento, uma nova cultura, uma nova visão do mundo.

O diagrama da Figura 1 apresenta uma síntese das características de um perfil conceitual, destacando o papel da linguagem nos processos de mediação didática.

As diferentes zonas do perfil conceitual de um indivíduo correspondem às suas diferentes formas de ver o mundo. Cada zona requer um processo de mediação didática e linguagem específica. Apesar das diferentes linguagens utilizadas em cada zona, a mediação didática do professor pode promover a interação das várias linguagens sociais com uma única linguagem, a partir da qual cada sujeito, imerso numa cultura, interpreta os fenômenos sob estudo.

\footnotetext{
${ }^{2} \mathrm{O}$ termo evolução não deve ser tomado aqui no sentido valorativo, de uma modificação para melhor, mas de mudanças de concepções em direção à concepção mais aceita pela ciência contemporânea. Fazendo uma analogia com o perfil epistemológico de Bachelard, a evolução no perfil epistemológico corresponde à aquisição de concepções cada vez mais racionais e mais distantes da postura realista ingênua.

${ }^{3} \mathrm{O}$ termo alfabetização cientifica, embora muito utilizado entre os que lidam com o ensino de Ciências, deve ser usado com cuidado, pois pode levar à idéia reducionista de que adquirir uma cultura científica é, simplesmente, conhecer os símbolos e representações usadas na Ciência.
} 


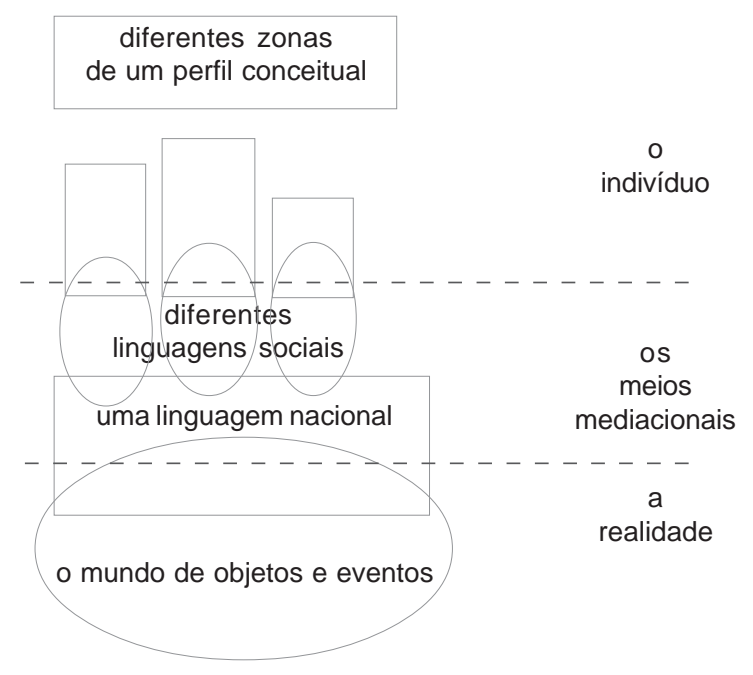

Figura 1. Características de um perfil conceitual (MORTIMER, 1997, p. 202).

O esquema apresentado acima parece retomar o debate em torno das idéias de Piaget e Vygotsky em relação à questão de a aprendizagem partir do sujeito, com ênfase para sua estrutura cognitiva, ou ser condicionada por fatores sociais que influenciam o processo de cognição do aprendiz. Este esquema, a nosso ver, representa uma tentativa de superar a abordagem dicotômica sujeito/contexto social no processo de aprendizagem, mostrando que tanto o sujeito, ao interagir socialmente, tende a mudar seu processo cognitivo, quanto o ambiente social, com seus condicionantes, interfere no processo de cognição do sujeito e, conseqüentemente, em sua aprendizagem.

Ao aplicar a noção de perfil conceitual ao conceito de molécula, Mortimer mostra a inadequação da discussão de um conceito central em Química de forma independente de seu contexto. Para ele, a dispersão conceitual proporcionada pelo perfil tem a vantagem de fazer perceber que a forma como se aborda o mundo está relacionada ao contexto no qual se está imerso (MORTIMER, 1997).

A preocupação de Bachelard com o ensino de Ciências de certa forma acompanha suas inquietações em relação ao processo de produção da Ciência. Para ele, o racionalismo aplicado ao objeto científico deve ser precedido da incorporação do pensamento racional pelo sujeito, de forma que "uma ontologia da idéia ensinada vem, então, revestir o racionalismo docente" (BACHELARD, 1977, p. 20). Para Bachelard, este racionalismo "exige aplicação de um espírito a outro" e guarda, a nosso ver, semelhanças com o processo pedagógico de mediação didática. Neste, a ação pedagógica exige uma racionalidade (docente) sempre vigilante, para superar obstáculos como, por exemplo, o desconhecimento, pelo professor, de que o aluno tem idéias pré-concebidas - normalmente revestidas de um realismo ingênuo, próprio do senso comum - que impedem, muitas vezes, a compreensão e apreensão dos conceitos científicos. Este obstáculo é chamado por Bachelard de obstáculo pedagógico. 
Sua trajetória como professor de Física e Química e suas reflexões sobre o ato de ensinar decorrentes dessa trajetória adiantaram, no campo do ensino de Ciências, um debate que só recentemente teve início, a partir da utilização do modelo de aprendizagem por mudança conceitual, já comentado. A idéia de que é importante conhecer as idéias prévias dos alunos para planejar estratégias de ensino de Ciências é, ainda hoje, um dos focos de estudo entre educadores dessa área, tanto dentro de uma perspectiva construtivista como fora dela. Ao admitir que o conhecimento científico tenha uma racionalidade diferente do senso comum, admite-se a existência de formas diferentes de conhecimento que vão estar presentes nas salas de aula de Ciências. Nesse sentido, a concepção de professor como um mediador entre conhecimentos muitas vezes conflitantes está, de alguma forma, presente na obra de Bachelard.

Outro aspecto da obra de Bachelard que atualmente faz parte dos debates sobre a formação do professor é a idéia de formação continuada. Embora não tenha feito referências diretas à formação docente, sua defesa do professor como um eterno estudante, sempre aberto à reflexão sobre o objeto científico, de forma que a razão esteja constantemente em estado de mobilização, mostra uma concepção de formação como constante renovação e defende uma prática docente que supere a mera transmissão de conhecimentos. Sobre isso, Bachelard diz: "é preciso também inquietar a razão e desfazer os hábitos do conhecimento objetivo. Deve ser, aliás, a prática pedagógica constante" (BACHELARD, 1996, p. 304).

Embora Bachelard não tenha se referido, explicitamente, à idéia de pesquisa na formação do professor, pode-se depreender de sua obra uma ênfase na construção do novo, na inventividade, na criação. Neste caso, ao defender um processo de descoberta do novo, recorrendo à história das idéias científicas, num processo de críticas e retificações constantes, Bachelard inova, para um homem da sua época, e, de alguma forma, introduz a idéia de pesquisa na formação docente. Ao criticar, por exemplo, a utilização que as pessoas fazem da mecânica newtoniana, reduzindo-a ao estudo da atração entre os corpos, sem utilizar os argumentos subjacentes, o autor chama a atenção para determinados hábitos intelectuais que impedem a renovação da razão. Para ele:

É preciso, pois, evitar o desgaste das verdades racionais que tem tendência a perder a apodicticidade e a tornar-se hábitos intelectuais. Balzac dizia que os solteirões substituem os sentimentos por hábitos. Da mesma forma, os professores substituem as descobertas por aulas. Contra essa indolência intelectual que nos retira aos poucos o senso da novidade espiritual, o ensino das descobertas ao longo da história científica pode ser de grande ajuda. Para ensinar o aluno a inventar, é bom mostrar-lhe que ele pode descobrir. (BACHELARD, 1996, p. 303)

O pensamento de Bachelard incentiva a inventividade no ato de ensinar, valorizando, nesse processo, a análise histórica do conhecimento científico. Por um processo por ele cha- 
mado de recorrência histórica, o conhecimento do passado é julgado, a partir do conhecimento do presente ${ }^{4}$.

Para ele, "O antigo deve ser pensado em função do novo", sendo essa a condição para fundamentar o racionalismo das ciências físicas contemporâneas (BACHELARD, 1996, p. 308). Nessa perspectiva, é importante que, no ensino, o professor tenha uma postura de constante questionamento sobre sua prática docente, a partir da reflexão sobre como ela tem se dado ao longo de toda sua vida profissional.

Esta atitude questionadora, mobilizadora da razão, que se apreende das idéias de Bachelard, vai em direção à defesa de uma formação docente reflexiva, como aquela proposta por Schön (2000) e outros autores, como Zeichner (1993), Nóvoa (2002) e Maldaner (2000). Defendendo a importância da pesquisa na formação docente, estes autores enfatizam o processo de ação e reflexão como forma de mobilizar os saberes docentes no sentido da solução dos problemas da prática. Assim, o processo de formação docente está sempre em construção, constituindo um movimento dialético de empiria/razão fundamental, não apenas para a produção do conhecimento científico, como defendido por Bachelard, mas, também, para a produção de qualquer saber profissional que garanta a autonomia do sujeito em formação.

Essa discussão mostra a pertinência, relevância e atualidade da epistemologia bachelardiana para os processos de ensino e de formação do professor, em especial, na área das ciências físicas, objeto do estudo filosófico de Bachelard.

\section{Referências}

ABD-EL-KHALICK, F.; LEDERMAN, N. G. The Influence of History of Science Courses on Students' Views of Nature of Science. Journal of Research in Science Teaching, Nova York, v. 37, n. 10, p. 1057-1095, 2000.

BACHELARD, G. O racionalismo aplicado. Trad. Nathanael C. Caixeiro. Rio de Janeiro: Zahar Editores, 1977.

A Filosofia do Não: filosofia do novo espírito científico. Trad. Joaquim José Moura Ramos. 5. ed. Lisboa: Editorial Presença, 1991.

A Formação do Espírito Científico: contribuição para uma psicanálise do conhecimento. Trad. Estela dos Santos Abreu. Rio de Janeiro: Contraponto, 1996.

\footnotetext{
${ }^{3}$ A noção de recorrência histórica tem sido criticada por historiadores da Ciência da linha continuista, pois é associada à noção de whiggismo que, do ponto de vista historiográfico, é considerada lamentável. Para detalhes sobre as críticas ao whiggismo ver Shapin, 1992, apud Henry, 1998. A nosso ver, ao propor esta noção Bachelard não pretende fazer um julgamento de valor, como se o conhecimento do presente fosse melhor que o do passado, como poderia parecer. Ao julgar o antigo em função do novo, ele reconhece, na Ciência contemporânea, uma racionalidade mais complexa e, portanto, mais adequada ao pensamento científico.
} 
Lôbo, S. F.

COBERN, W. W. Worldview Theory and Conceptual Change in Science Education.

Science Education, Salem, Massachussets, v. 80, n. 5, p. 579-610, 1996.

COMTE, A. Discurso sobre o espírito positivo. Trad. Maria Ermantina Galvão G.

Pereira. São Paulo: Martins Fontes, 1990.

HENRY, J. A Revolução científica e as origens da ciência moderna. Trad. Maria Luíza X.A.Borges. Rio de Janeiro: Jorge Zahar, 1998.

LÔBO, S. F. Epistemologia bachelardiana e o progresso filosófico das Ciências Físicas: implicações na Química e no ensino de Química. In: SILVA FILHO, W. J. (Org).

Epistemologia e Ensino de Ciências. Salvador: Arcádia, 2002. p. 245-257.

LOPES, A. R. C. Contribuições de Gaston Bachelard ao Ensino de Ciências. Enseñanza de las Ciencias, Barcelona, v. 11, n. 3, p. 248-274, 1993.

Livros didáticos: obstáculos ao aprendizado da ciência Química. Química Nova, São Paulo, v. 15, n. 3, p. 254-261, 1992.

MALDANER, O. A. A formação inicial e continuada de professores de Química: professor/pesquisador. Ijuí: Unijuí, 2000.

MATTHEWS, M. R. Science teaching: the role of history and philosophy of Science. New York: Routledge, 1994.

MORTIMER, E. F. Conceptual change or conceptual profile change? Science Education, Salem, Massachussets, v. 4, n. 3, p. 267-287, 1995.

Construtivismo, mudança conceitual e ensino de Ciências: para onde vamos?

Investigações em Ensino de Ciências, Porto Alegre, v. 1, n. 1, p. 20-39, 1996.

Para além das fronteiras da Química: relações entre filosofia e ensino de Química. Química Nova, São Paulo, v. 20, n. 2, p. 200-207, 1997.

Pressupostos epistemológicos para uma metodologia de ensino de Química: mudança conceitual e perfil epistemológico. Química Nova, São Paulo, v. 15, n. 3, p. 242-249, 1992.

NÓVOA, A. Formação de professores e trabalho pedagógico. Lisboa: EDUCA, 2002.

SCHÖN, D. A. Educando o profissional reflexivo: um novo design para o ensino e a aprendizagem. Trad. Roberto Cataldo Costa. Porto Alegre: Artes Médicas, 2000.

STINNER, A.; WILLIAMS, H. Conceptual change, history, and Science stories.

Interchange, The Netherlands, v. 24, n. 1-2, p. 87-103, 1993.

VYGOTSKY, L. S. Pensamento e linguagem. Lisboa: Edições Antídoto, 1979.

ZEICHNER, K. M. A formação reflexiva de professores: idéias e práticas. Lisboa: EDUCA, 1993.

Artigo recebido em abril de 2007 e aceito em julho de 2007.

100

Ciência \&̊ Educaşão, v. 14, n. 1, p. 89-100, 2008 